\title{
Ultrafast Nonlinear Signal Processing in Silicon Waveguides
}

Oxenløwe, Leif Katsuo; Mulvad, Hans Christian Hansen; Hu, Hao; Ji, Hua; Galili, Michael; Pu, Minhao; Palushani, E.; Yvind, Kresten; Hvam, Jørn Märcher; Clausen, Anders

Total number of authors:

11

Published in:

OFC/NFOEC Technical Digest

Publication date:

2012

Document Version

Publisher's PDF, also known as Version of record

Link back to DTU Orbit

Citation (APA):

Oxenløwe, L. K., Mulvad, H. C. H., Hu, H., Ji, H., Galili, M., Pu, M., Palushani, E., Yvind, K., Hvam, J. M., Clausen, A., \& Jeppesen, P. (2012). Ultrafast Nonlinear Signal Processing in Silicon Waveguides. In OFC/NFOEC Technical Digest (pp. OTh3H.5). Optical Society of America.

\section{General rights}

Copyright and moral rights for the publications made accessible in the public portal are retained by the authors and/or other copyright owners and it is a condition of accessing publications that users recognise and abide by the legal requirements associated with these rights.

- Users may download and print one copy of any publication from the public portal for the purpose of private study or research.

- You may not further distribute the material or use it for any profit-making activity or commercial gain

- You may freely distribute the URL identifying the publication in the public portal 


\title{
Ultrafast Nonlinear Signal Processing in Silicon Waveguides (invited paper)
}

\author{
L.K. Oxenløwe, H.C.H. Mulvad, H. Hu, H. Ji, M. Galili, M. Pu, E. Palushani, K. Yvind, J. M. Hvam, A.T. \\ Clausen and P. Jeppesen \\ DTU Fotonik, Technical University of Denmark, Building 343, DK-2800 Lyngby, Denmark \\ lkox@fotonik.dtu.dk
}

\begin{abstract}
We describe recent demonstrations of exploiting highly nonlinear silicon waveguides for ultrafast optical signal processing. We describe wavelength conversion and serial-to-parallel conversion of $640 \mathrm{Gbit} / \mathrm{s}$ data signals and $1.28 \mathrm{Tbit} / \mathrm{s}$ demultiplexing and all-optical sampling. OCIS codes: (060.4510) Optical communications; (190.4360) Nonlinear optics, devices
\end{abstract}

\section{Introduction}

From a power consumption perspective, all-optical signal processing may be suitable for functionalities where many bits are processed in a few devices [1]. This is the case for e.g. wavelength conversion and all-optical regeneration, especially if very high channel bit rates are considered. Furthermore, if the optical signal processing can be achieved in CMOS-compatible silicon waveguides, then ultra-fast, energy-efficient photonic chips may become a reality for simple processing applications, which may be interesting for future ultra-fast serial data links, e.g. in data centres, between servers, in super-computers or even for niche applications in the core transport network..

In this paper we review some promising all-optical functionalities based on silicon photonics. In particular we use nano-engineered silicon waveguides enabling efficient phase-matched four-wave mixing (FWM) for ultra-highspeed optical signal processing of ultra-high bit rate serial data signals. We show that silicon can indeed be used to control Tbit/s serial data signals [2], perhaps paving the way for future ultra-fast optical chips. From an energy perspective, the most promising functionalities are those that process many bits in few devices, e.g.. conversion-type functionalities where e.g. a full serial data signal is converted to some other format. In such a scheme, all the bits in the serial signal are processed in the same device. We will describe various potentially energy-efficient schemes of conversion, focusing on wavelength conversion [3] and serial-to-parallel conversion [4], all using Si waveguides.

\section{Silicon photonics for optical signal processing - background}

Nonlinear signal processing in silicon by the nonlinear optical Kerr effect has been described and used for many applications over the last 5-10 years, e.g. NRZ-to-RZ conversion [5], regeneration, multi-casting, multiplewavelength source, monitoring, demultiplexing and many more, see e.g. [6-25]. Most of these demonstrations rely on ultrafast FWM or even two-photon absorption (TPA). Adding other nonlinear materials to Si slot waveguides can induce a high nonlinearity but avoid the detrimental nonlinear absorption of silicon. Such materials could be organic molecules [26-27], recently used to enable a $40 \mathrm{Gbit} / \mathrm{s}$ data modulator [28] and demultiplexing $170 \mathrm{Gbit} / \mathrm{s}$ [29].

\section{Ultra-fast optical signal processing: recent demonstrations at DTU Fotonik}

In the DTU Fotonik Tbit/s test-bed, an up-to $1.28 \mathrm{Tbit} / \mathrm{s}$ data signal is generated by optical time division multiplexing (OTDM) of a $10 \mathrm{Gbit} / \mathrm{s}$ base rate data signal based on very short optical pulses (300 fs FWHM), see principle sketch in Fig. 1 (left). The pulses are data modulated (amplitude or phase) and multiplexed in a fibre delay line multiplexer up to $1.28 \mathrm{Tbit} / \mathrm{s}$. This signal may then be used to test a variety of components and functionalities, including transmission [30] and as described here signal processing using silicon. Fig. 1 shows the basic principle of multiplexing from low rate data streams, e.g. $10 \mathrm{Gbit} / \mathrm{s}$, to e.g. $1.28 \mathrm{Tbit} / \mathrm{s}$. An eye diagram of the generated $1.28 \mathrm{Tbit} / \mathrm{s}$, as measured with a commercial ultrafast optical sampling oscilloscope, is shown in Fig. 1 (middle). Fig. 1(right) shows the same signal measured with a silicon sampling systems, revealing superior timing resolution [2].
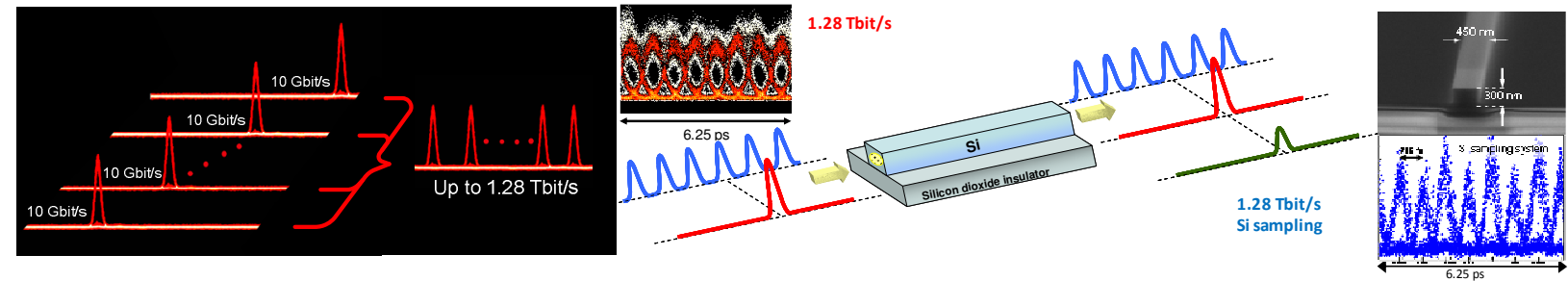

Figure 1. Tbit/s signal generation and principle of four-wave mixing optical signal processing in a silicon waveguide. Right: Image of typical waveguide structure and a sampled eye diagram of a 1.28 Tbit/s data signal using the Si waveguide [2]. 
Fig. 1 (right) shows an image of the used nanowire [31], which has tapered end-sections providing low coupling loss (1.5 dB per facet). Fig. 1 (middle) shows the principle of pulsed FWM. When a control pulse co-propagates with a data pulse, an idler copy is generated at the pump pulse rate. We have shown that we can process Tbit/s data signals using FWM in an all-Si nanowire, by demonstrating demultiplexing and optical sampling of a $1.28 \mathrm{Tbit} / \mathrm{s}$ data signal [2], and moreover, recently shown that the processing rate can be increased to 320 and $640 \mathrm{GHz}$, when we did 320 and $640 \mathrm{Gbit} / \mathrm{s}$ wavelength conversion [3][10], see Fig. 2 below. Fig. 2 shows $640 \mathrm{Gbit} / \mathrm{s}$ DPSK wavelength conversion results together with BER measurements for $320 \mathrm{Gbit} / \mathrm{s}$. This is the highest signal processing speed reported using silicon, and figure 2 shows full BER characterization for all tributary channels. All channels are within the standard FEC requirements with a $7 \%$ overhead, corresponding to $595 \mathrm{Gbit} / \mathrm{s}$ error-free conversion. This functionality is promising for low energy consumption: we used as low as $110 \mathrm{fJ} / \mathrm{bit}$ pump energy for the $640 \mathrm{Gbit} / \mathrm{s}$ case. We have previously shown $95 \mathrm{fJ} / \mathrm{bit}$ for $640 \mathrm{Gbit} / \mathrm{s}$ wavelength conversion using highly nonlinear fiber (HNLF) [31]. Wavelength conversion is more challenging than demultiplexing, as all time channels need to be switched simultaneously, whereas a demultiplexer only switches one channel at a time. It is still not well established which effect the free carriers generated through two-photon absorption have on the FWM processing speed, so the demonstration of ultra-high-speed wavelength conversion indicates that it may be possible to isolate the FWM effect from the TPA/FCA effects and allow for ultra-fast processing. Here this was done simply by keeping the CW pump power below the TPA threshold. Note that the BER limitations in the $640 \mathrm{Gbit} / \mathrm{s}$ wavelength conversion result is due to OSNR limitations, stemming from the relatively poor conversion efficiency $(-30 \mathrm{~dB})$ of the used device and the insertion loss, resulting in a very modest FWM output power.
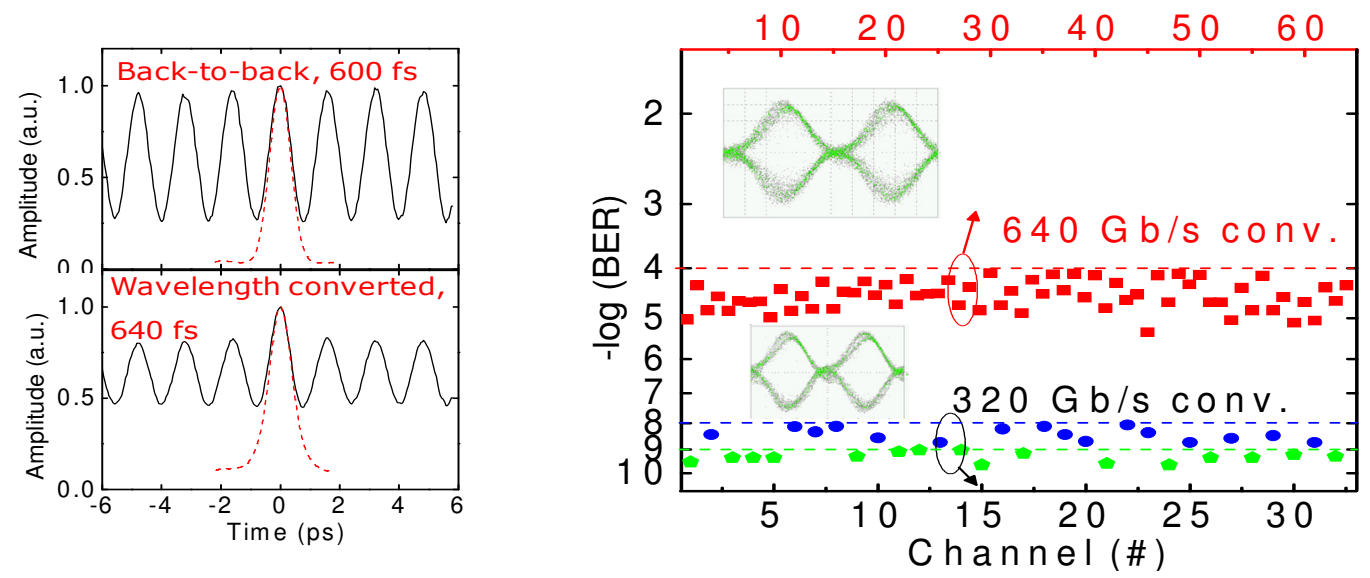

Figure 2. $640 \mathrm{Gbit} / \mathrm{s}$ wavelength conversion using FWM in a nonlinear silicon waveguide. Left: autocorrelation traces of the original $640 \mathrm{Gbit} / \mathrm{S}$ DPSK signal and the converted $640 \mathrm{Gbit} / \mathrm{s}$ DPSK signal. There is a slight pulse broadening owing to limited filters after conversion. Right: BER results for 320 and $640 \mathrm{Gbit} / \mathrm{s}$ DPSK wavelength conversion [3] for all data channels. All results are within FEC requirements, as all channels are below BER 10E-4.

As mentioned above, 1.28 Tbit/s demultiplexing has been demonstrated [2], but a single-channel demultiplexer may not be the best choice in terms of energy efficiency. If the demultiplexing can be based on a conversion scheme like the wavelength conversion, it may be more efficient [1]. With the development of the time lens concept [32-33], or equivalently the optical Fourier transformation (OFT) technique [34], a versatile new tool for manipulating optical waveforms has been created. It has for instance been used for dispersion compensation [34], timing jitter suppression [33], Ethernet packet synchronization [35], optical pulse shaping of e.g. flat-top pulses [36], and recently also for serial-to-parallel data conversion [37-38]. The technique allows for spectral-to-time domain and time-to-spectral domain transformations. In [4], we showed this could be done in a $\mathrm{Si}$ waveguide. The basic principle is sketched in Fig. 3 (left). The OFT is based on FWM in the Si waveguide by chirped pump and data pulses. If the pump is dispersed twice as much as the data, spectral compression of the converted channels is achieved, and each temporal channel is furthermore converted to a separate WDM channel. This is because each OTDM channel overlaps with a different part of the pump spectrum, and will be converted to different idler wavelengths. Balancing the dispersion of the pump and data with the said factor of two gives optimal spectral compression. In [4], $25 \mathrm{GHz}$ spaced DWDM channels were generated this way from a $640 \mathrm{Gbit} / \mathrm{s}$ OTDM data signal. Fig. 3 (middle) shows the involved spectra. Note that the pump spectrum is made flat-top in order to also create a flat-top temporal waveform to overlap with more than half of the OTDM channels. Fig. 3 (right) shows the converted WDM channels and their corresponding BER performance. 40 of the 64 OTDM tributaries were simultaneously demultiplexed to individual $25 \mathrm{GHz}$ spaced DWDM channels with BER performance below the FEC 

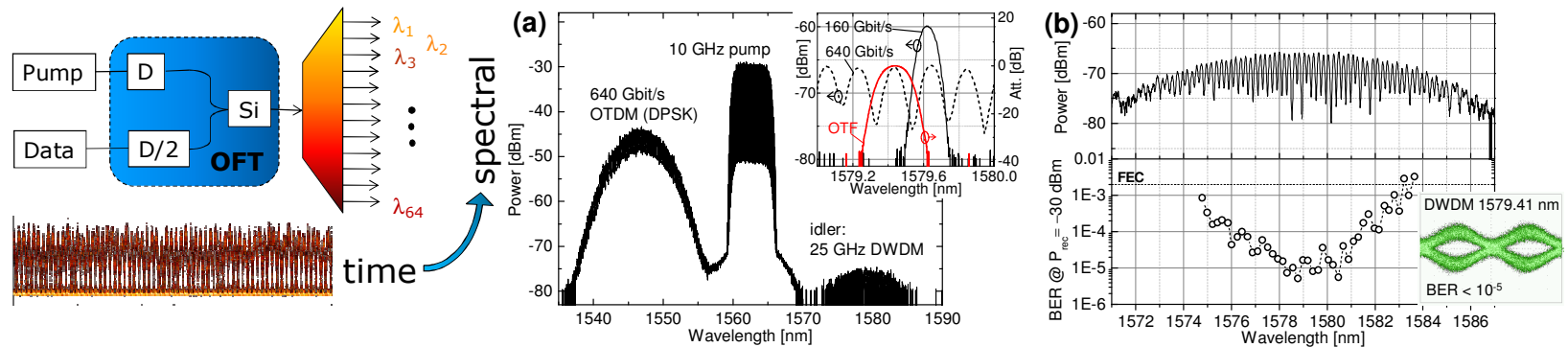

Figure 3. $640 \mathrm{Gbit} / \mathrm{s}$ serial-to-parallel conversion in a nonlinear silicon waveguide using the optical time lens or optical Fourier transformation (OFT) technique. Left: schematic setup. Middle (a): involved spectra, of the $640 \mathrm{Gbit} / \mathrm{s}$ DPSK data signal, the 10 GHz flat-top pump and the resulting $25 \mathrm{GHz}$ spaced DWDM channels (inset: zoom-in on DWDM channels and optical tunable filter (OTF) transfer function to filter out individual DWDM channels. Right (b): converted DWDM channels and corresponding BER performance. 40 channels are within FEC limits of 2E-3 BER, i.e. more than half of all the 64 channels are simultaneously demultiplexed [4].

limit. This means that only two OFT units would be needed to demultiplex all channels, instead of 64 individual demultiplexers. This type of conversion may thus prove more energy efficient and more practical.

\section{Conclusion}

We have described recent advances in the use of silicon nanowires for all-optical signal processing. We have focused on conversion experiments and shown wavelength conversion and serial-to-parallel conversion of $640 \mathrm{Gbit} / \mathrm{s}$ data signals.

\section{References}

[1] R. Tucker et al, IEEE Photonics Journal, Vol. 3, No. 5, October 2011 Page 821, DOI: 10.1109/JPHOT.2011.2166254 (2011)

[2] H. Ji et al, OFC 2010, postdeadline paper PDPC7

[3] H. Hu et al, OFC'2011, postdeadline paper PDPA8

[4] H.C.H. Mulvad et al, ECOC'2011, postdeadline paper

[5] Y. Ding et al, Optics Express, Volume 19, Issue 7, pp. 6471-6477 (2011)

[6] S. F. Preble et al, Nature Photonics 1 293-296, (2007)

[7] R. Salem et al, Nature Photonics 2, 35-38 (2008)

[8] B. G. Lee et al, CLEO 2009, CThBB1

[9] F.Li et al, Optics Express, Vol.18, No.4 (2010)

[10] H. Hu et al, OFC 2011, paper OWG6

[11] R.Salem et al., Nature Photonics 2, 35, 2008

[12] B. Corcoran et al., Opt. Express 18, 2010

[13] A. Biberman et al ECOC 2010, paper We.7.E.3

[14] M. A. Foster et al, Nature 441, 960-963 (2006)

[15] M. A. Foster et al,", Nature 456, 81-84 (2008)

[16] J.S. Levy et al, Nat.Phot. 4, 37, (2010)

[17] D. Moss et al," Electron. Lett. 41, pp 320 (2005)

[18] T. Liang et al Opt. Express 13, pp 7298 (2005)

[19] O. J.. Boyraz et al, Opt. Express 12, pp 4094 (2004)

[20] R. L. Espinola et al, Opt. Express 13, pp 4341 (2005)

[21] H. Rong et al, Opt. Express 14, pp 1182 (2006)

[22] K. Yamada et al, IEEE Photon. Technol. Lett. 18, pp 1046 (2006)

[23] Q. Lin et al, Opt. Express 14, pp 4786 (2006)

[24] R. Dekker et al, Opt. Express 14, pp 8336 (2006)

[25] Y. -H. Kuo, Opt. Express 14, pp 11721 (2006)

[26] J. Leuthold et al, Nature Photonics, Vol.4, 535-544 (2010)

[27] C. Koos et al, Proc. OFC2008, paper PDP25

[28] L. Alloatti et al, Proc. ECOC 2010, paper Tu.5.C.4

[29] C. Koos et al, Nature Photon. vol 3, 216-219 (2009)

[30] H. Hu et al, ECOC 2010, Paper P4.18.

[31] M. Pu, et al., Optics Communications, vol. 283, Oct. 2010, pp. 3678-3682.

[31] H. Hu et al., Optics Express, vol. 18, (2010)

[32] B.H. Kolner J.Quant. Electron. vol. 30 (1996)

[33] L.F. Mollenauer et al, CLEO 2002, CPDB1-1

[34] T. Hirooka et al, JLT 24(7), (2006)

[35] H. Hu Areal et al, ECOC'2011, paper Tu.3.K.4

[36] E. Palushani et al, J.Quantum Electron., vol. 45, no. 11, pp. 1317-1324, (2009)

[37] H.C.H. Mulvad et al, OFC 2011, paper OThN2

[38] E. Palushani et al, IEEE J. Select. Topics in Quantum Electron., Issue: 99, Digital DOI: 10.1109/JSTQE.2011.2131121 (2011) 